\title{
A Novel Approach to teach Design and Analysis of Algorithms Course
}

\author{
${\text { Gautami Shingan', } \text { Varsha Lokare }^{2} \text {, Nagaraj Dharwadkar }}^{3}$ \\ ${ }^{123}$ Department of Computer Science and Engineering, Rajarambapu Institute of Technology, Rajaramnagar, Maharashtra,India. \\ ${ }^{1}$ gautami.shingan@ ritindia.edu \\ ${ }^{2}$ varsha.lokare@ritindia.edu \\ ${ }^{3}$ nagaraj.dharwadkar@ritindia.edu
}

\begin{abstract}
Most of the soft branch courses are imaginary, that takes a lot of time to understand the concepts and visualize them. In Computer Science, Design and Analysis of algorithm course is one of them where we design the algorithmic solution to a real-time problem and analyze the complexity of the algorithm. In this paper we have shown the different learning tools to understand nature, working and systematic implementation of the problem by visualizing it, also we have discussed suitable strategies to design and implement same and compared the complexity of algorithms. Further, we have compared the impact of an activity on students by comparing assessment strategies ISEI and ISE-II, also by taking feedback from students before and after conduction of activity.
\end{abstract}

Keywords: Visualization Tools, Role Play, Animation, Simulator, Design and Analysis of Algorithms, Logical Skills etc.

\section{Introduction}

The development of logical thinking and visualization ability is one of the difficult tasks in Computer Science branch. Design and Analysis of Algorithms course is mainly focused on the real-time problems that take a lot of time using a bruit force approach. The drawback of bruit force approach is it takes lot of time to solve the problem. This approach works good for small scale problem but when the complexity of problem gets increased, the performance of this approach degrades. If we understand the nature of problem and categorize into the algorithmic strategy which are available in the literature then we can easily solve the problem efficiently by reducing time and space require to get solution and improve the performance. In this paper, we mainly focus on four algorithmic strategies like Divide and Conquer, Greedy

\section{Gautami Shingan}

Department of Computer Science and Engineering,

Rajarambapu Institute of Technology, Rajaramnagar,

Maharashtra, India.

gautami.shingan@ritindia.edu

Method, Dynamic Programming and Backtracking. To understand the problem, students the reason behind choosing this approach is that the human brain interprets through use of visualization are easy to recall and retain in future than verbal or text data.

The article published by Thermopylae Sciences And Technology, human brain processes images 60,000 times faster than text, and 90 percent of information transmitted to the brain is visual. [1] Since, we are visual by nature, we mainly focus on Visualization concepts to learn the different algorithmic strategies. In this paper, we mainly focus on the understanding of problem-solving ability by visualizing it. To visualize the problem we have selected the following activities as:

1. Role Play

2. Visualization Tools

3. Simulators and Animations

Section 2 is emphases on methodologies used to understand the systemic way to solve the problem by applying some set of instructions repeatedly on a given set of data. Section 3 represented the impact of activity-based learning on students to retain knowledge. In this section we also compared the problem-solving ability of students in ISE-I and ISE-II tests conducted in the academic year 2019-20. Finally, section 4 shows the concluding remarks of the activity.

\section{Methodology}

Before starting activity-based learning students should have knowledge of different algorithmic strategies. Hence, they can try to apply different strategies over the problem and identify specific and suitable strategy using brainstorming.

\section{Visualization tools:}

Most of the real-time problems on objects are in terms of cities, stations, and other resources that can be mapped into nodes and connections between them is shown using the links. This representation is called a graphical representation of the problem. Such type of problems can be delivered using visualization tools. In such tools either we can create a graph as per our requirement or use the predefined problems so solve it using a systematic approach called an algorithmic way. This tool is used to solve the problems that categorize into Dynamic Programming and Greedy Strategy[3][4].

In the classroom we have solved the problems like Depth First Search (DFS), Breadth First Search (BFS), All Pair Shortest Path, Single Source Shortest Path etc. 


\section{Outcome:}

- Understand algorithmic strategy of given problem.

- Design the systematic approach to solve problem and develop an algorithm.

\section{Activity Plan:}

1) Give a real time problem to solve and ask students to identify an algorithmic strategy.

2) Provide links of visualization tools to students for solving using an appropriate algorithm.

Link1 DFS:

https://www.cs.usfca.edu/ galles/visualization/DFS. $\underline{\mathrm{html}}$

Link 2 BFS:

https://www.cs.usfca.edu/ galles/visualization/BFS. $\underline{\mathrm{html}}$

3) If they are not able to understand by own then course teacher has to show the demonstration of a problem.

4) Also, ask them to apply by taking different examples.

5) Once they understand the examples then again perform the brainstorming and ask to write an algorithm on the way which they have solved the problem.

6) This approach leads to design an algorithm to the problem.

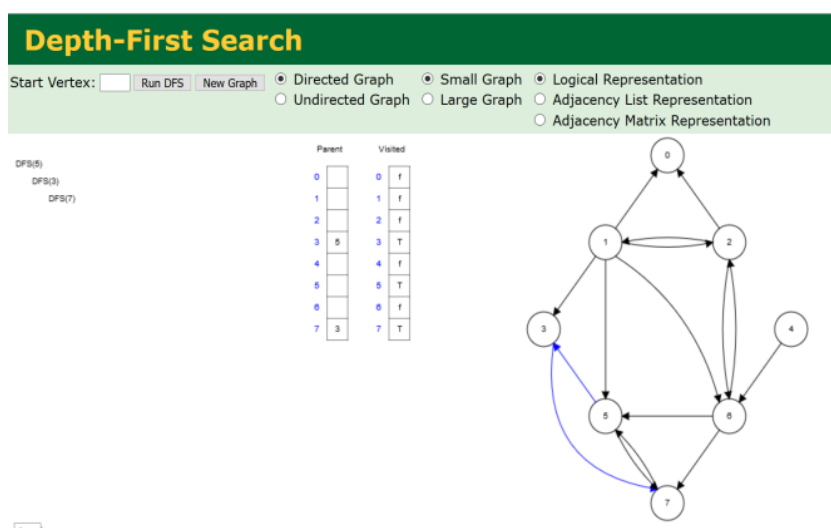

Fig. 1 Depth First Search Link 1

Role Play:

Another type of problems, the input is in terms of numbers where we cannot visualize the data properly, in such type of problems we can apply role-play activity effectively[6][7]. This activity is applied to Divide and Conquer strategy for Merge Sort and Quick Sort problem which is very tedious to solve using pivot value.

\section{Outcome:}

- Apply algorithm to solve the problem.

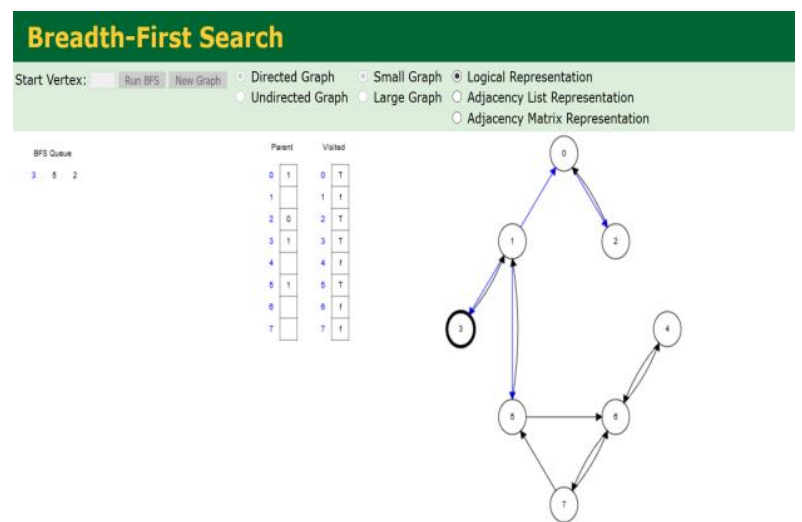

Fig. 2 Breadth First Search Link 2

\section{Activity Plan:}

1) Explain the working of Quick Sort using powerpoint presentation and Blackboard.

2) Prepare yellow cards with random numbers and ask students to pick up any card and stand in a queue randomly.

3) To perform the recurrence formula over all elements and trace the current status of an algorithm, call two more students and name them as variable ' $\mathrm{i}$ ' and variable ' $\mathrm{j}$ '.

4) Apply the algorithm steps on a given set of elements until we get a sorted list.

5) The audience (rest students in the classroom) should involve during the execution of an algorithm.

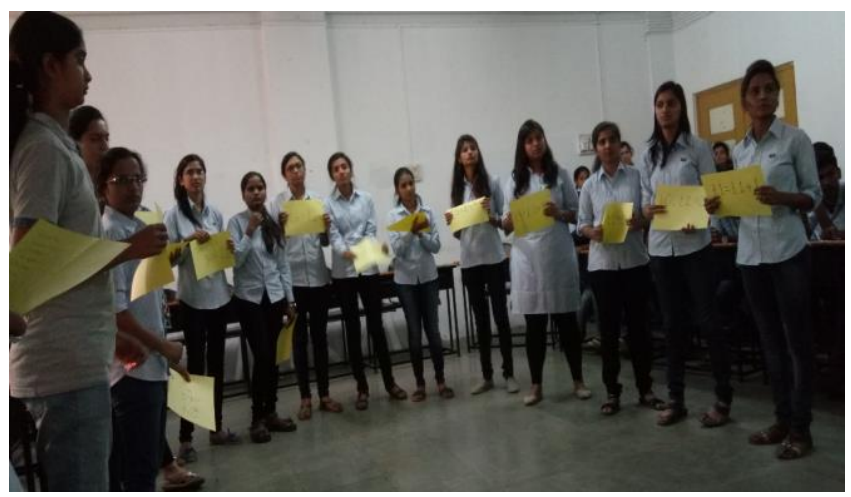

Fig. 3 Role Play to perform Sorting using Divide and Conquer

Above figure shows the role play activity implemented for the Quick Sort algorithm.

Simulation and Animation:

Another category of problem whose input is neither represented in terms of graphically nor numerically such kind of problem is very difficult to visualize on a blackboard. Some examples of such type of problems are: N-queen problem, Maze Problem etc. For such category, we have used simulation and animation[5]. Simulation is applied to backtracking approach and animation is applied to problems like Knapsack problem, All Pair Shortest Path, Single Source Shortest Path and so on.

\section{Outcome:}

- Implement solution of the problem using algorithms. 


\section{Action Plan:}

1) Explain the problem in detail and its algorithm.

2) Ask them to apply manually (but, a problem with students as they could not trace the current status algorithm).

3) To resolve it, share simulation link with students to ask them to see the working of a simulator and animations.

Link1:

http://algoanim.ide.sk/index.php?page=showanim\&i $\underline{\mathrm{d}=61}$

Links2:

http://eightqueen.becher-sundstroem.de/

4) Once they understand the working of problem then instruct them to design a Pseudocode for the same and also analyze the performance of the algorithm.

N-Queen Problem we used two simulation Links that are shown in figure 4 and 5.

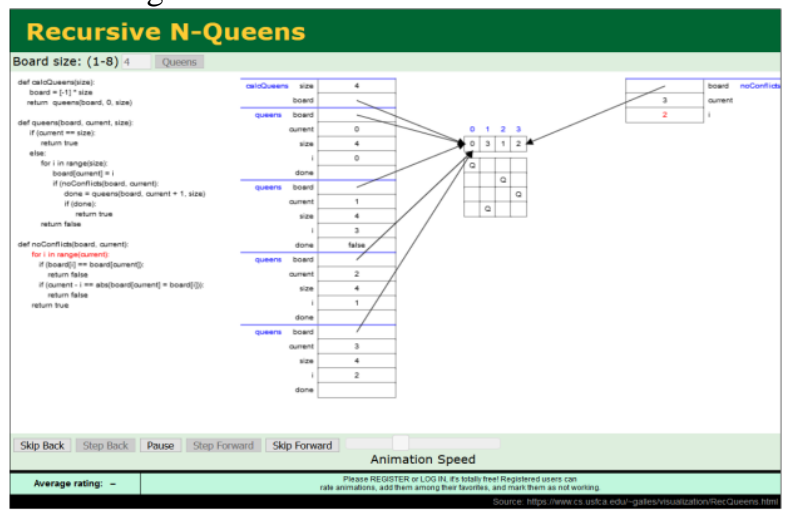

Fig. 4 N-Queen Problem Link1
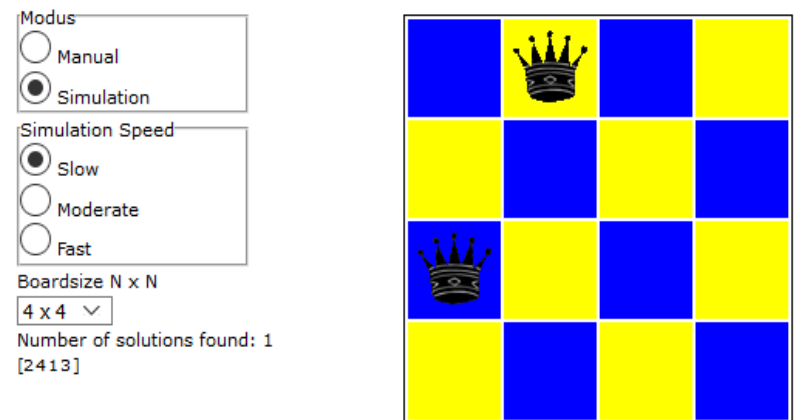

Fig. 5 N-Queen Problem Link2

The list of few links used to show animations in the classroom are:

Divide and Conquer Link:

https://www.youtube.com/watch?v=wVPCT1VjySA

Knapsack Problem:

https://www.youtube.com/watch?v=sVB99cpaTmw

\section{Results and Analysis}

The course, Design and Analysis of Algorithm is very difficult for the students. Most of the times they understand the concepts during the lectures but unable to attend the questions during examination. All these activities works efficiently and effectively on the course. The main goal to conduct this activity is to understand the concepts of course to students. The activities are tested over 67 number of students of Third year B. Tech class.

Initially, we have conducted (In Semester Examination -I) ISE-I on real-time problem Solving. It has been observed that students get low grades. The average grades achieved of students is 5 out of 10 . To understand students difficulties, we have taken feedback from them. The structure of feedback is shown in the following Table 1.

Table 1. Structure of Feedback

\begin{tabular}{|c|c|c|}
\hline $\begin{array}{l}\text { Sr. } \\
\text { No. }\end{array}$ & \multicolumn{2}{|c|}{ Questionaries } \\
\hline 1. & \multicolumn{2}{|c|}{$\begin{array}{l}\text { I can able to analyse the nature of problem and } \\
\text { categories it into appropriate strategy? }\end{array}$} \\
\hline & A. Strongly Agree & B. Agree \\
\hline & C. Disagree & D. Strongly Disagree \\
\hline 2. & \multicolumn{2}{|c|}{$\begin{array}{l}\text { I can solve the problem with optimized solution } \\
\text { using the strategy that I have finalized? }\end{array}$} \\
\hline \multirow[t]{2}{*}{3.} & A. Strongly Agree & B. Agree \\
\hline & C. Disagree & D. Strongly Disagree \\
\hline 4. & \multicolumn{2}{|c|}{$\begin{array}{l}\text { I can visualize the problem while solving it using } \\
\text { algorithm? }\end{array}$} \\
\hline & A. Strongly Agree & B. Agree \\
\hline & C. Disagree & D. Strongly Disagree \\
\hline \multirow[t]{3}{*}{5.} & \multicolumn{2}{|c|}{$\begin{array}{l}\text { I can design the algorithm using the set of } \\
\text { instructions followed during finding an optimal } \\
\text { solution? }\end{array}$} \\
\hline & A. Strongly Agree & B. Agree \\
\hline & C. Disagree & D. Strongly Disagree \\
\hline 6. & \multicolumn{2}{|c|}{$\begin{array}{l}\text { I can analyse the performance of the algorithm using } \\
\text { time and space complexity? }\end{array}$} \\
\hline & A. Strongly Agree & B. Agree \\
\hline & C. Disagree & D. Strongly Disagree \\
\hline
\end{tabular}

Feedback before conduction of activities

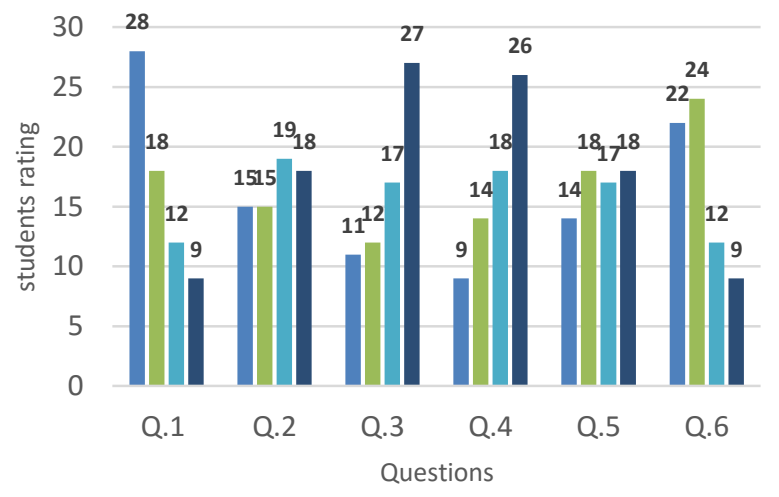

$\square$ Strongly Agree $\square$ Agree $\square$ Disgree $\square$ Strongly Disagree

Fig. 6 Analysis of before conduction of activities

From the graph, we analyzed that, question 1 and 6 have less number of students who disagree, question 2 and 5 has an average rating in all categories and question 3 and 4 has high 
rating to disagree and strongly disagree. Hence, we had decided to concentrate mostly on these two.

To see the impact of activities, we took two feedbacks from students one is before conducting activity shown in figure 6 and second after conducting activities shown in figure 7.

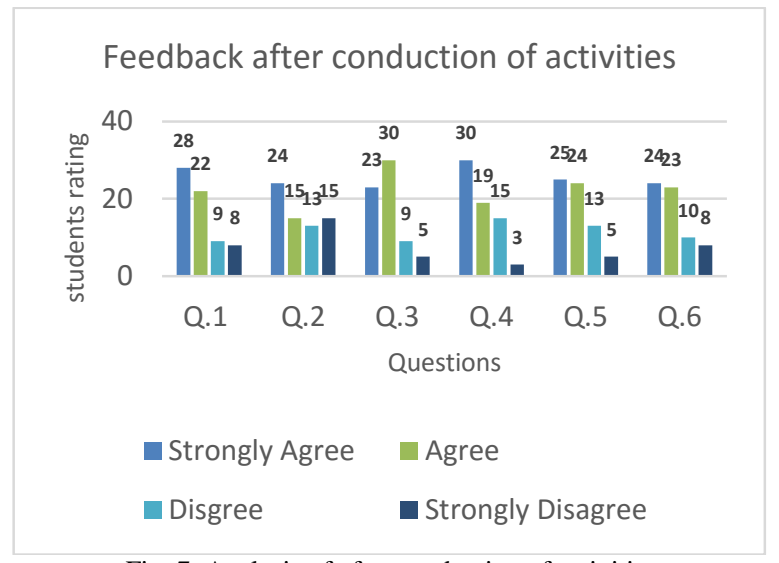

Fig. 7 Analysis of after conduction of activities

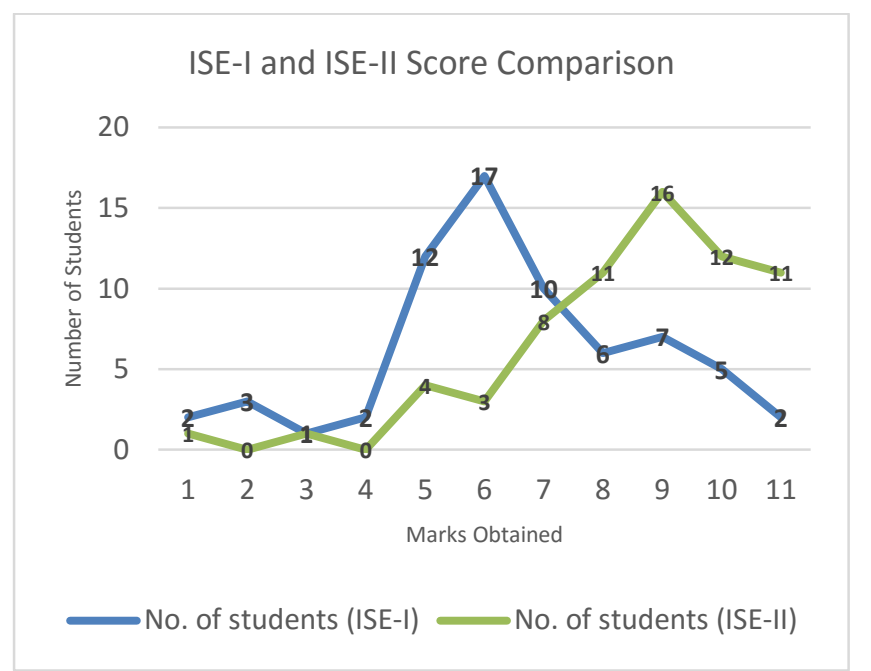

Fig. 8 Analysis of after conduction of activities

Further, we have analyzed scores in ISE-I and ISE-II. The average score in ISE-I is 5.47 out of 10 . However, In ISE-II, It has been increased to 7.52 out of 10 .

\section{Conclusions}

Now a days, activity-based learning is very important to understand the delicate and tough concepts in engineering filed with minimum time. It also helps to create a joyful learning environment by conducting interactive and collaborative sessions in the classroom. The basic concepts get clear by solving various problems by visualizing the problems using simulators, animations, and visualization tools. The thinking and problem-solving ability of students get established. The result is improved by $20.5 \%$ in ISE-II as compare to ISE-I.

\section{References}

[1]Article: Humans Process Visual Data Better, "http://www.tsciences.com/news/humans-process-visual-data-better"
By THERMOPYLAE SCIENCES + TECHNOLOGY in September 15, 2014.

[2] GS, K. Nagraj Dharwadkar, "Student Quality Circle: Skilful Learning Environment” Journal of Engineering Education Transformations, 2017.

[3] Gautami G Shingan, Bharati K Ugale," A Holistic Approach for Teaching Design and Analysis of Algorithms Course in the Department of Computer Engineering", Journal of Engineering Education Transformations, 2018.

[4] Mr. Prakash M. Jadhav and Ms. Varsha T. Lokare, "A Holistic Approach for Teaching Data Structure Course in the department of Information Technology", Journal of Engineering Education Transformations, 2017.

[5] Dr. MOHAMMEDTAQIUDDINTAHER," Impact of Simulation based and Hands-on Teaching Methodologies on Students' Learning in an Engineering Technology Program", conference on American Society for Engineering Education, 2014.

[6] Varsha T Lokare, Prakash M Jadhav, Snehal S Patil,"An Integrated Approach for Teaching Object Oriented Programming $(\mathrm{C}++)$ Course", Journal of Engineering Education Transformations, 2018.

[7] Bharati K Ugale, Gautami G Shingan,"A Novel Approach to Improve Logical and Critical Thinking through Collaborative Learning and Using Visualization Tools", Journal of Engineering Education Transformations, 2018. 